\title{
Towards engagement: A comparison of fan groups in the context of a major South African football club
}

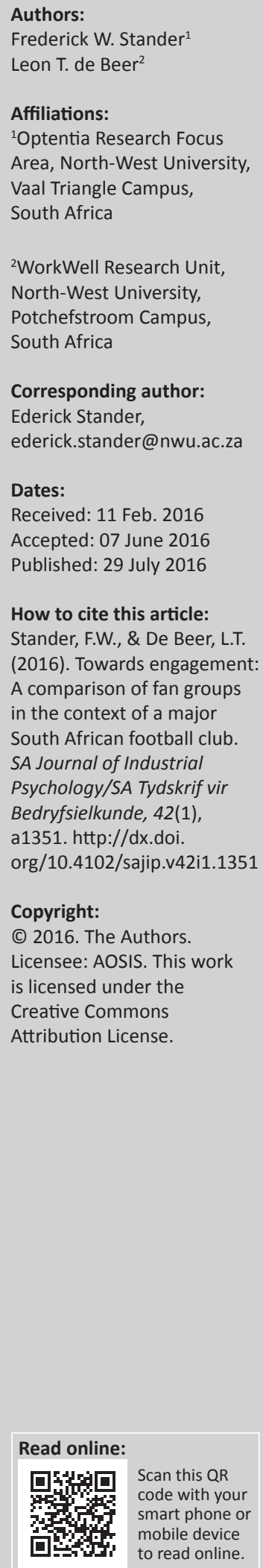

Orientation: The commercial growth of sport clubs is often a direct consequence of the level of engagement of its fans. However, limited research has been done to understand how the engagement experience of these fans could be enhanced.

Research purpose: The objective of this research was to evaluate whether differences exist amongst groups of sport fans in terms of their levels of engagement. This is conducted on the basis of customer engagement - relationship marketing - and market segmentation theories, and in an effort to inform practical strategies that could be used to leverage engagement. By establishing that differences do exist between segments of sport fans, practical strategies could be developed based on such differences.

Research approach, design and method: A cross-sectional, quantitative design was utilised in this study. A convenience sample of 430 adult fans of one of South Africa's largest and best supported professional football clubs participated in the study. Two fan groupings were compared, namely fans who belonged to a formal supporters' branch of the club versus fans who did not, and fans who frequented the social media platforms of such club versus fans who did not. Multigroup confirmatory factor analysis and latent variable modelling were implemented to compare groups of fans in terms of sport fan engagement. Measurement invariance was reviewed to compare the equivalence of measurement between the groups.

Main findings: Statistical analysis revealed greater levels of fan engagement amongst fans that form part of formal supporters' branches as well as amongst fans who regularly visit the sport club's social media platforms.

Practical/managerial implications: By making use of supporters' branches and social media, practical engagement strategies are available to professional sport clubs that seek to enhance the engagement experience of their fans. These strategies could assist clubs in developing customised intervention programmes specifically for this purpose.

Contribution/value-add: The study puts forward practical suggestions with regards to engagement strategies that professional sport clubs can consider in their efforts to enhance the commercial performance of their teams through greater engagement.

\section{Introduction}

The supporter (or fan) is often classified as an important partner in the context of achieving industry growth and development in the realm of professional sport (Bing et al., 2015; Madrigal, Hamill \& Gill, 2013). Fundamentally, the sport fans generates social and commercial currency to the benefit of a sport club, expands the reach of such club's brand and enhances the overall success of the club (Giampiccoli, Lee \& Nauright, 2015; Pichot, Tribou \& O'Reilly, 2008; Pillay \& Bass, 2009). Supporters fulfil this role in exchange for various forms of gratification, for example to belong to a social group, to associate with club success and to consume the club's products and service offerings (Cottingham, Phillips, Hall, Gearity \& Carroll, 2014; De Burca, Brannick \& Meenaghan, 2015; Monfarde, Tojari \& Nikbakhsh, 2014; Trail \& James, 2001; Wang, Zhang \& Tsuji, 2011). The growth and expansion potential of a club is thus firmly vested in its fans (Monfarde et al., 2014; Stander \& Van Zyl, 2016).

Due to the influence that fans have in the commercial and social advancement of professional clubs, Yoshida, Gordon, Nakazawa and Biscaia (2014) put forward the concept of fan engagement, an interest kindled by the buoyant growth rate of the business of sport globally, which has been resilient despite challenging economic realities (Baller, 2015; Giampiccoli et al., 2015; Koortzen \& Oosthuizen, 2012). This resilience has been attributed directly to engagement levels of fans 
globally, who have continued and even enhanced their expenditure on the activities of their favourite professional clubs - despite the pressures of a declining global economic climate (Bing et al., 2015; Giampiccoli et al., 2015; Madrigal et al., 2013). High levels of fan engagement witnessed amongst sport supporters have positioned the industry to currently be worth more than US\$600 billion (US) globally, as evaluated by KPMG (2014, p. 5). Even in particularly stressed economies, such as South Africa, it is estimated that the business of sport will enjoy a sustained positive growth trajectory, with a valuation of R19.5 billion projected for 2017 (PricewaterhouseCoopers, 2015, p. 16). Growth of the sport industry, both locally and abroad, has been fuelled by sustained levels of fan engagement; promulgating renewed attention to the clear role of the sport fans as a partner to professional clubs (Koenderman, 2013; Madrigal et al., 2013).

Considering the status of the fan as a key commercial partner, it is somewhat surprising that limited research exists pertaining to the fundamentals of the fan engagement experience. No published research could be found on pragmatic strategies for enhancing the sport fan engagement experience, neither directly, nor by comparing the fan engagement experience of different clusters, groups or segments of sport fans. This research attempted to address this shortcoming by comparing the fan engagement experience of different groups of fans of a large South African professional football club, in an affirmation of the role of the sport fans as a key commercial partner and in an effort to amplify and service this role better.

\section{Literature review}

\section{Sport fan engagement}

Wann, Melnick, Russell and Pease (2001) used the term 'fan', often popularly used and derived from the word 'fanatic', to describe individuals who willingly invest resources - either emotional or financial - in supporting their favourite professional sport club. 'Fans' do not represent mere spectators to or watchers of sport, but rather a fraternity of people who diligently and over a prolonged period of time display their allegiance to a specific sport team of which they are fervent supporters (Wann et al., 2001). These individuals often subscribe to the unique culture or ethos of a club, immerse themselves within a community of other fans who share their passion for the club and loyally embark on various endeavours that promote club interests, such as attending live matches at the stadium or purchasing the branded merchandise of the club (Allison, 2013; Funk, Beaton \& Alexandris, 2012; Humphries \& Smith, 2006; Martin, 2013). In their togetherness, sport fans of a particular team form the essence of what can be described as such club's collective currency in society. This community of people represents the club as ambassadors, generates awareness of the club in the vastness of their numbers and generally serves the club's commercial and social interests by consuming the properties of the professional club as a business entity (Heere \& James, 2007). This is based on brand community, the loyalty that sport fans experience in relation to their club and which influences their interaction with that club (Guimaraes,
Stride \& O'Reilly, 2016). When fans feel part of this community, they experience empowerment, which motivates them to engage in positive consumer behaviours of interaction with the brand of their favourite team (Katz \& Heere, 2015). Sport fan engagement encapsulates the passion that sport fans have for their chosen club, which in turn drives their investment in such club and ultimately leads to the growth and expansion of the club's interests (Martin, 2013; Wann et al., 2001).

Sport fan engagement comprises three dimensions, namely management cooperation, prosocial behaviour and performance tolerance (Yoshida et al., 2014). Management cooperation refers to the willingness of fans to make an active contribution to the administrative efforts of their chosen sport clubs' management teams and the extent to which fans attempt to ensure the events success of the club (Auh, Bell, McCleod \& Shih, 2007; Yoshida et al., 2014). This willingness is reflected in positive observable behaviour, such as fans giving club management constructive feedback on how to enhance the club's fan experience or conducting themselves in a manner that is consistent with the positive image of the club at matches (Auh et al., 2007; Doherty, 2013). Prosocial behaviour reflects the extent to the level of community and interaction sought by fans with other people who also support their preferred sport team (Yoshida et al., 2014). Doherty (2013) describes this as the intensity of dialogue that fans seek with each other, either directly by conversing on the progress of the club or by making use of digital platforms. Performance tolerance is indicative of the extent to which fans will display behaviours of loyalty to the club, even during challenging times, such as when the team is experiencing a losing streak (Auh et al., 2007; Yoshida et al., 2014). It reveals the diligence with which sport fans choose to support their clubs, wearing club apparel regardless of the results of the team and pledging allegiance to the club (De Ruyter \& Wetzels, 2000).

\section{The commercial value of engaged fans}

Fan engagement provides a compelling strategic advantage to clubs, as it is engagement with the brand personality that moves people to actively consume club products and service offerings (Yoshida et al., 2014). Across the world, and within the domain of all flourishing professional sporting codes, clubs leverage high levels of engagement of fans to enjoy sustained development despite sluggish economic growth prospects (KPMG, 2014). Numerous examples in the literature have articulated direct links between fan engagement and outcomes that can be considered favourable to the growth of professional sport clubs. Hall (2009), as well as Yoshida, Gordon, Heere and James (2015) argue that engaged fans will actively seek opportunity to attend the specially arranged events of their preferred sport club; such as attending games or being present at special activations such as fan opportunities for meeting the players of that club.

Engaged sport fans commit financial resources and emotional energy in seeking interaction with their favourite professional clubs (Funk et al., 2012). Martin (2013) attributed sport 
consumer spending on club merchandise directly to levels of fan engagement, arguing that an engaged fan is likely to purchase club products, such as match tickets, attire and general merchandise, on a frequent and continued basis. Stander and De Beer (2016) found that the dimensions of fan engagement as put forward by Yoshida et al. (2014), predicted both stadium match attendance and merchandise expenditure amongst 767 South African sport fans supporting various professional clubs.

The link between fan engagement and purchasing behaviours may be explained by the customer engagement (CE) theory. $\mathrm{CE}$ theory argues that consumers, when considering a purchase of a product or subscribing to a particular idea, will conduct a cognitive and/or affective evaluation of the extent to which such a product, service or idea is aligned to their own personal values, preferences or moral fabric (Brodie, Hollebeek, Juric \& Ilic, 2011). When the consumer perceives congruence between his or her personal values and the offering of the product, service or idea, that consumer is likely to frequently display behaviours of consumption (Van Doorn et al., 2010).

CE theory is part of a nomological network of variables related to the concept of relationship marketing, a school of thought which proposes that brands that are dependent on the long-term loyalty of its consumers (like sport clubs) should seek to foster close relationships with customers based on emotional affinity, rather than focusing on shortterm sales (Berry, 1983; Hollebeek, Conduit \& Brodie, 2016; Morgan \& Hunt, 1994; Vohra \& Bhardwaj, 2016). Relationship marketing is complex as it is reliant on trust and identity with a brand, but when such trust and identity is established, repeated purchases are highly likely, and commercial growth will follow (Bee \& Kahle, 2006, 2015; Hollensen, 2015). Fan engagement is related to relationship marketing as it reflects the absorption with a brand a sport fan experiences and is indicative of the long-term commitment and emotional investment the fan makes into the professional sport club's brand, making it an influential predictor of buying decisions (Bee \& Kahle, 2006, 2015; Yoshida et al., 2014).

\section{Research gap}

Research is required to direct the fan engagement effort of professional sport clubs in an attempt to better service its primary 'people partner', namely their fans. This should lead to heightened investment in products and services on the part of these fans and ultimately will benefit the growth of the entire sports industry (Allison, 2013; Bing et al., 2015; De Burca et al., 2015). Literature that outlines practical and clear engagement strategies that can be applied by professional clubs, remains limited. This gap is partly addressed in this work with the comparison of fan groups of one of South Africa's best supported professional football clubs. This comparison is utilised as the basis for proposing practical engagement strategies.

\section{Segmentation of fans and their different experience of engagement}

In this study, an attempt is made to differentiate clusters of fan groups based on market segmentation theory in the realm of sport consumerism. Fillis and Mackay (2014) argue that sport consumers (fans) can be segmented culturally, socially, and demographically in terms of their team engagement behaviours. This view is shared by Bouzdine-Chameeva, Ferrand, Valette-Florence and Chanavat (2015), who state that a population of fans is heterogeneous as far as the brand relationships and cognitive- and/or emotive evaluation are concerned; with fans of different backgrounds or preferences differing fundamentally in the way they consume sport. Crawford (2009) states that sport fans are 'different and distinct in their practices and culture' (p. 25). Bale (1993), as well as $\mathrm{Hu}$ and Cole (2016), express that fans vary in the intensity with which they support their favourite team, with deeply loyal and ardent fans usually seeking very particular platforms to converse with - and about their favourite professional club.

The arguments of these authors are consistent with traditional market segmentation theory, which postulates that an active consumer market can be clustered into different categories of customers who share certain behaviours, attributes or traits (Cross, Belich \& Rudelius, 2015; Hunt \& Arnett, 2004; Wedel \& Kamakura, 2012). This is summarised by Jenkins and McDonald (1997): 'The basic premise of market segmentation is that a heterogeneous group of customers can be grouped into homogenous clusters or segments, each requiring differing applications of the marketing mix to service their needs' (p. 17). It is this differing application to segments of the sport consumer market which currently is left unexplored, particularly in view of the fan engagement experience of sport consumers. By evaluating whether differences do in fact exist pertaining to the fan engagement experience of different groups of fans, an early empirical understanding of possible practical strategies to enhance engagement experience could be facilitated. This should enhance knowledge of better servicing sport fans and will yield scientific value in finding early evidence for the development of practical strategies that can further grow the buoyant industry of sport (Crawford, 2004, 2009).

Two distinct groups of fans were evaluated for the purposes of this research. Firstly, fans who were part of a formal supporters branch of the participating club were compared with fans who were not. Zagnoli and Radicchi (2009) stated that it is not uncommon for some of the world's leading professional sport clubs to have numerous formally organised supporters' branches. These branches are usually geographically bound and form part of an extensive network of loyal fans who seek active community with other supporters of their favourite team in a geographically proximate manner (Madden, 2012). Zagnoli and Radicchi (2009) refer to supporters' branches as mechanisms that clubs use for 'value co-creation'. Supporters' branches, which greatly extend the brand footprint of the professional sport clubs, mobilise fans 
to take ownership over the interests of their favourite team in the geographical territories closest to them (Millward, 2012). A fan has to formally apply to be enrolled into a supporters' branch and is then inducted into a structured process of organised activities that the branch conducts in an effort to promote club interests. These activities include organising attendance of matches through transport from the local region, liaising with club headquarters for special events in the area and distributing official merchandise of the club to the local community. The practice of supporters' branches is widespread globally and has been used fruitfully in South Africa as well, particularly by some of the major football clubs. The most loyal fans of a sport club decide to join a supporters' branch, as these individuals go above and beyond the requirements of a standard supporter and sacrifice time and resources on a regular basis to promote the interests of their favourite team (Madden, 2012; Zagnoli \& Radicchi, 2009). Although not yet extensively explored, it is also plausible that fans that form part of their favourite club's supporters' branches will be more engaged than those who are not.

The second group comparison made in this research was between fans that make frequent use of the social media platforms of the professional sport club compared to fans who do not. Social media has fundamentally changed the way in which sport clubs communicate with fans (Witkemper, Lim \& Waldburger, 2012). Shank and Lyberger (2014) comment that, in the digital age, social media vastly expands the reach of professional sport clubs to converse with fans in remote areas all over the world. The professional sport club seeking to remain at the forefront of communicating with fans has no choice but to embark on the strategic leveraging and value that is made possible through the use of digital technologies (Shank \& Lyberger, 2014; Witkemper et al., 2012). Social media includes the wide arrange of digital platforms that make two-way communication possible in a community of people (Leonardi, Huysman \& Steinfield, 2013). In this paper, the social media platforms considered were Facebook and Twitter. Facebook is the world's largest social media network and is structured based on a digital 'page' dedicated to a particular person/organisation (case in question the football club under investigation). Twitter also is a social networking service enabling registered 'users' and 'followers' to publicise short, summarised messages of information on the specific service owner (which is, like Facebook, also an individual or organisation).

McCarthy, Rowley, Jane Ashworth, and Pioch (2014) believe that the growth of social media users necessitated the development of dedicated social media strategies by major professional sport clubs around the world. Sport fans who are really interested in the results of their clubs and particularly their day-to-day interactions and developments view social media as a useful platform to gather information and provide input for consideration by the club management teams (O'Shea \& Alonso, 2012; Witkemper et al., 2012). Frequent social media users are usually better informed about club events as they enjoy immediate access and are also known to be more directly involved in conversing with other fans on club developments (De Mel \& Boccardo, 2014; McCarthy et al., 2014). It is thus likely that the social media users are also more engaged with the activities of the professional sport club.

Based on market segmentation theory, this paper argues that clusters of fans will differ with regard to their levels of engagement. To investigate this, two clusters in two different fan categories are evaluated; namely fans who are part of a supporters' branch versus fans that are not, and fans that frequent social media platforms of the club regularly versus fans who do not. An observed, differentiation in these market segments may lead to the development of targeted interventions that could enhance overall fan engagement, in the process generating commercial value to the club. Based on the positive relationship between fan engagement and expenditure (explained by CE - and relationship marketing theory), and informed by market segmentation theory and the literature outlined above, the hypotheses for this study are formulated.

\section{Hypotheses}

This research seeks to determine whether differences exist amongst groups of sport fans in terms of their levels of engagement. The research will compare two groups of fans of one of South Africa's largest football clubs, namely, (1) fans who belong to a supporters' branch of the club versus fans who do not, and (2) fans who make use of the social media platforms of the club as opposed to fans who do not. The following hypotheses are formulated:

Hypothesis 1: Fans who are part of a formal supporters' branch of a professional sport club will be more engaged than fans who are not.

Hypothesis 2: Fans who make use of social media platforms of a professional sport club will be more engaged than fans who do not.

\section{Method}

\section{Research approach}

This research made use of a quantitative, cross-sectional design, recording responses of large numbers of participants at one particular point in time (Salkind, 2009). The participants were divided into four clusters based on two separate groups, one being fans who were part of their club's supporters' branches versus fans who were not, and two being fans who make use of social media platforms of the club versus fans that do not. The clusters were evaluated in isolation; that is, it was possible that a fan who was part of a supporters' branch could also be a regular social media user.

\section{Participants and procedure}

The convenience sample included 430 adult fans of one of South Africa's largest and best supported professional 
football clubs. The participating football club was wellsuited to the study, comprising of 315 formal supporters' branches right across South Africa, and at the time of the study having just more than 2.2 million Facebook 'followers' (through 'likes') and 620000 'followers' on Twitter. The mean age of the sample was 34.39 (SD = 10.34). Table 1 presents the demographic composition of the participating sample.

The research was conducted on-site at a stadium during matches of the participating football club. Permission was obtained from the football club to set up a research station that could be managed before the match, during half-time and after the match. Fans participated in the study by completing self-reporting questionnaires. All participants were briefed on the voluntary nature of their participation and assured of the confidentiality of their responses. Participants were also reminded that they could withdraw at any time of the study. The research formed part of a larger project. No possible risk was envisioned for participants through participation in the study. Finally, the project was presented for formal ethical clearance to the Research Committee of the Faculty of Economic Sciences and Information Technology of the North-West University. Clearance for the study was provided.

\section{Measurement instruments}

\section{Fan engagement}

Fan engagement was measured with the Fan Engagement Scale (FES) (Yoshida et al., 2014). The FES comprises nine items, three items for each of the three fan engagement dimensions namely management cooperation, prosocial behaviour and performance tolerance. Items for example include 'The employees of my football team get my full cooperation' (management cooperation), 'I often interact with other fans to discuss issues related to my team' (prosocial behaviour) and 'I display the logo of my team on my clothing even if they do not do well' (performance tolerance). These items are scored on a seven-point Likert-type scale with possible responses ranging from strongly disagree to strongly

\begin{tabular}{llcc} 
TABLE 1: Respondents' & biographic information $(N=430)$. & \\
\hline Variable & Category & Frequency $(f)$ & $\%$ \\
\hline Gender & Male & 295 & 68.60 \\
& Female & 135 & 31.40 \\
Race & Asian & 6 & 1.40 \\
& Black & 384 & 89.72 \\
& Mixed race & 22 & 5.14 \\
& White & 11 & 2.57 \\
& Other & 5 & 1.17 \\
Level of education & Grade 11 and below & 126 & 29.30 \\
& Grade 12 & 163 & 37.91 \\
& Degree & 56 & 13.02 \\
& Post Graduate Degree & 38 & 8.84 \\
Branch membership & Yes & 254 & 61.95 \\
& No & 156 & 38.05 \\
Digital media use & None & 106 & 26.37 \\
& At least once a week & 296 & 73.63 \\
\hline
\end{tabular}

Note: Where totals do not add up to 421 participants $(100 \%)$, it is due to missing values. agree. Yoshida et al. (2014) found the FES to be reliable, with an overall Cronbach's alpha score of 0.86 . In a local study, Stander and De Beer (2016) established internal consistency for all the FES dimensions, namely management cooperation ( $\alpha=0.85)$, prosocial behaviour $(\alpha=0.70)$ and performance tolerance $(\alpha=0.90)$.

\section{Biographical information}

Group differences amongst the sample group were measured by means of a biographical questionnaire that asked whether participants were part of a supporters' branch of the club or not and whether they made use of the club social media platforms (at least once a week) or not.

\section{Data analysis}

Confirmatory factor analysis (CFA) was applied with Mplus 7.4 (Muthén \& Muthén, 2015). All items were used with no forced correlation of errors on observed indicators or parcelling strategies based on any modification indices. Therefore, latent variable modelling was implemented with the observed indicators matched to their corresponding latent factors. Latent variable modelling is advantageous as it considers error measurement of the variables, which is not the case with sum scored methods. The maximum likelihood estimator was used in the estimation process of all models and parameters. Fit indices for the model were: Comparative fit index (CFI), Tucker-Lewis index (TLI), Root mean square error of approximation (RMSEA), Square root mean residual (SRMR), Akaike information criterion (AIC) and Bayesian information criterion (BIC). For the CFI and TLI values of 0.90 are considered acceptable; for the RMSEA and SRMR a value of 0.08 or below; and for the AIC and BIC the lowest values are considered the most appropriate; that is, when comparing models, the lowest values indicate the best fitting model (Van de Schoot, Lugtig \& Hox, 2012).

Specifically, to compare the means between the groups, multigroup CFA was conducted. Mplus standardises the mean values of the reference group to 0.00 for comparison with the other group. Furthermore, measurement invariance was also investigated to compare the equivalence of measurement between the groups. Measurement invariance investigates whether the factor structure (configural model), loadings (metric model) and intercepts (scalar model) in the two groups are equivalent (Van de Schoot et al., 2012).

If all three of these models are equivalent, strong measurement invariance can be claimed and the means between the groups can be compared. However, if it is not evident the researcher should investigate which of the model parameters are not equivalent and free these parameters in a test of partial measurement invariance. If partial measurement invariance is achieved, means can still be compared. If invariance cannot be found, means cannot be meaningfully compared. Statistically significant differences do not imply that a real difference exists beyond the numeric values; that is, practical difference. To address 
this possibility, this study calculated Cohen's $d$ effect size value based on the mean differences. A large effect is considered as 0.80 and above, a medium effect $0.50-0.79$ and a small effect 0.20-0.49 (Cohen, 1988). Additionally, the 95\% confidence intervals for the effect sizes were also reported.

\section{Results}

\section{Fit statistics for the measurement models}

Firstly, it was investigated whether a one-factor or a threefactor solution for fan engagement was the best fit to the data in order to continue with the analyses. Results showed that the three-factor model (CFI $=0.95$; TLI $=0.93$; RMSEA $=0.07$; SRMR $=0.03 ;$ AIC $=11539.91 ;$ BIC $=11661.19)$ was a substantially better fit to the data compared to the one-factor model $(\mathrm{CFI}=0.82 ; \mathrm{TLI}=0.76$; $\mathrm{RMSEA}=0.13$; $\mathrm{SRMR}=0.08$; $\mathrm{AIC}=11835.46 ; \mathrm{BIC}=11944.61)$. Table 2 presents the Cronbach's alpha coefficient values and correlation matrix for the latent variables. All of the reliability values were acceptable $(\alpha>0.70)$ and all of the latent variables components of fan engagement were correlated with each other with large effect size $(r>0.50$; Cohen, 1988).

Next, two measurement models based on the three-factor structure were tested with a multigroup approach, one model based on the grouping pertaining to branch membership (Model 1; Branch membership or not) and the other pertaining to social media usage (Model 2; Not at all versus at least once a week). Results showed that both models had acceptable fit to the data based on the criteria specified, with CFI and TLI $>0.90$; RMSEA and SRMR $<0.08$. The results are presented in Table 3.

\section{Measurement invariance of fan engagement in the groups}

Table 4 presents the results of the measurement invariance testing based on branch membership.

Evident from Table 4, the test for measurement invariance between the branch groupings showed measurement invariance (without any modifications); that is, equivalent factor structure, loadings and intercepts. This indicated that the means between the groups for the fan engagement latent variable components could be reliably and substantially compared.
The initial measurement invariance model based on media use only showed configural invariance; that is, an equivalent factor structure for fan engagement was evident. Upon investigation of modification indices, it was shown that freeing the intercept of item 6 in the no social media use group could make a significant gain. Indeed, freeing this intercept resulted in (partial) measurement invariance for the comparison of means between the no social media use group and the group who frequented social media at least once a week. Table 5 presents the results of the measurement invariance testing based on media use with the freed intercept.

\section{Mean values, variances and standard deviations for the groups}

Tables 6 and 7 provide the mean values with variance and standard deviation for each of the groups based on the scores obtained from the latent fan engagement constructs. The 0.00 means is for the reference group, as Mplus standardises the values of latent means in the reference group to 0.00 for comparison with the other group. Therefore, it is observable that the mean values on the fan engagement components were higher in the group which indicated supporter branch membership as well as higher for the group who indicated they frequent social media (the digital platforms Facebook and Twitter) of the sport club at least once a week. However, it is important to consider the practical effect sizes of the differences in means between the groups and these results are subsequently presented.

\section{Effect sizes for the mean differences between the groups}

Table 8 presents the effect sizes for the mean differences between the groups.

When the group with branch membership was compared to the group who were not members of a supporters' branch, the scores on all the latent components of fan engagement were much higher in the group with branch membership. This provides support for Hypothesis 1. Specifically, management cooperation was higher for the branch member group, bordering on a large practical positive difference $(d=0.79 ; 95 \%$ CI $[0.69$, 0.89]; medium effect). The group with branch membership also scored higher on prosocial behaviour $(d=0.58 ; 95 \% \mathrm{CI}$

TABLE 2: Reliabilities and correlation matrix for the latent variables of fan engagement.

\begin{tabular}{lcccc}
\hline Variables & Reliability & Management cooperation & Prosocial behaviour & Performance tolerance \\
\hline Management cooperation & 0.85 & 1.00 & - & - \\
Prosocial behaviour & 0.72 & $0.62 \dagger$ & - & 1.00 \\
Performance tolerance & 0.92 & $0.63 \dagger$ & $0.69 \dagger$ & 1.00 \\
\hline
\end{tabular}

Note: All correlations statistically significant $p<0.001$.

$\dagger$, Large practical effect.

TABLE 3: Results of the measurement models for the multigroup analysis.

\begin{tabular}{|c|c|c|c|c|c|}
\hline Model & $d f$ & CFI & TLI & RMSEA & SRMR \\
\hline Branch membership and non-membership & 60 & 0.95 & 0.94 & 0.07 & 0.07 \\
\hline No media use and using at least once a week & $59 \dagger$ & 0.93 & 0.91 & 0.07 & 0.06 \\
\hline
\end{tabular}

$\uparrow$ See measurement invariance section in Table 4

$d f$, degrees of freedom; CFI, Comparative fit index; TLI, Tucker-Lewis index; RMSEA, Root mean square error of approximation; SRMR, Standardised root mean square residual. 
TABLE 4: Results of the invariance testing based on branch membership.

\begin{tabular}{lccc}
\hline \multicolumn{1}{c}{ Models compared } & $\boldsymbol{\Delta} \boldsymbol{\chi}^{2}$ & $\boldsymbol{d f}$ & $\boldsymbol{p}$-value \\
\hline Metric against configural & 12.013 & 6 & 0.061 \\
Scalar against configural & 20.691 & 12 & 0.056 \\
Scalar against metric & 7.963 & 6 & 0.240 \\
\hline
\end{tabular}

$\Delta \chi^{2}$, change in chi-square; $d f$, degrees of freedom.
TABLE 5: Results of the invariance testing based on media use.

\begin{tabular}{lccc}
\hline Models compared & $\Delta \chi^{2}$ & $d f$ & $p$-value \\
\hline Metric against configural & 6.912 & 6 & 0.329 \\
Scalar against configural & 14.395 & 11 & 0.212 \\
Scalar against metric & 8.070 & 5 & 0.152 \\
\hline
\end{tabular}

$\Delta \chi^{2}$, change in chi-square; $d f$, degrees of freedom.

TABLE 6: Variances, means, and standard deviations of fan engagement in the branch groups.

\begin{tabular}{|c|c|c|c|c|}
\hline Group comparison: Branch & Component & Variance & Mean & Standard deviation \\
\hline \multirow[t]{3}{*}{ No branch membership } & Management cooperation & 1.170 & 0.00 & 1.082 \\
\hline & Prosocial behaviour & 1.292 & 0.00 & 1.137 \\
\hline & Performance tolerance & 2.493 & 0.00 & 1.579 \\
\hline \multirow[t]{3}{*}{ Branch membership } & Management cooperation & 1.015 & 0.820 & 1.007 \\
\hline & Prosocial behaviour & 1.173 & 0.637 & 1.083 \\
\hline & Performance tolerance & 1.103 & 0.643 & 1.050 \\
\hline
\end{tabular}

TABLE 7: Variances, means, and standard deviations of fan engagement in the media groups.

\begin{tabular}{|c|c|c|c|c|}
\hline Group comparison: Media & Component & Variance & Mean & Standard deviation \\
\hline \multirow[t]{3}{*}{ Does not visit online media } & Management cooperation & 1.159 & 0.000 & 1.077 \\
\hline & Prosocial behaviour & 1.788 & 0.000 & 1.337 \\
\hline & Performance tolerance & 2.612 & 0.000 & 1.616 \\
\hline \multirow[t]{3}{*}{ Visits at least once a week } & Management cooperation & 1.176 & 0.270 & 1.084 \\
\hline & Prosocial behaviour & 0.924 & 0.416 & 0.961 \\
\hline & Performance tolerance & 1.377 & 0.468 & 1.173 \\
\hline
\end{tabular}

TABLE 8: Mean difference effect sizes with confidence intervals at the $95 \%$ level.

\begin{tabular}{|c|c|c|c|c|c|}
\hline Group & Comparison & Component & Effect size $\dagger$ & Confidence interval & Confidence interval \\
\hline \multirow[t]{3}{*}{ Branch } & Membership versus non-membership & Management cooperation & $0.79 \ddagger$ & $95 \% \mathrm{Cl}$ & $0.69,0.89$ \\
\hline & & Prosocial behaviour & $0.58 \ddagger$ & $95 \% \mathrm{Cl}$ & $0.47,0.69$ \\
\hline & & Performance tolerance & $0.51 \ddagger$ & $95 \% \mathrm{Cl}$ & $0.38,0.63$ \\
\hline \multirow[t]{3}{*}{ Media } & At least once a week versus no use & Management cooperation & $0.25 \S$ & $95 \% \mathrm{Cl}$ & $0.15,0.36$ \\
\hline & & Prosocial behaviour & $0.39 \S$ & $95 \% \mathrm{Cl}$ & $0.28,0.49$ \\
\hline & & Performance tolerance & $0.36 \S$ & $95 \% \mathrm{Cl}$ & $0.23,0.49$ \\
\hline
\end{tabular}

$\uparrow$, Cohen's $d$; $\ddagger$, medium effect; $\S$, small effect.

$\mathrm{Cl}$, confidence interval.

$[0.47,0.69]$; medium effect) and performance tolerance $(d=0.51$; $95 \%$ CI $[0.38,0.63]$; medium effect). The group who frequented social media at least once a week or more had higher scores on all of the latent fan engagement components compared to the group who did not use these platforms at all. Hypothesis 2 is thus supported. The largest mean difference effect sizes in order were: Prosocial behaviour ( $d=0.39 ; 95 \%$ CI $[0.28,0.49]$; small effect), performance tolerance ( $d=0.36$; $95 \%$ CI [0.23, 0.49]; small effect) and management cooperation $(d=0.25 ; 95 \% \mathrm{CI}[0.47,0.69]$; small effect).

\section{Discussion and practical implications}

By establishing that applications for different fan groups would be heterogeneous in terms of the engagement experience and consistent with the argument of BouzdineChameeva et al. (2015), this study proposed that knowledge of pragmatic interventions would emerge to enhance total fan engagement, drawing from positive findings amongst the groups under investigation.

To effect this research goal, two clusters of fan groups were evaluated. Firstly, fans who formed part of organised and formal supporters' branches of the club were compared to fans that did not form part of such branches. It was logical to argue that fans who belonged to an organised supporters' branch would be more engaged than those who did not, as these individuals demonstrate behaviours that signal their intent to permanently form part of communities who conduct directed and deliberate activities to promote club interests (Millward, 2012; Zagnoli \& Radicchi, 2009). Secondly, fans that make use of the club's social media platforms (Facebook and Twitter) were compared to fans that do not make use of these digital communication options. According to Shank and Lyberger (2014), accessibility to the sport club is greatly enhanced through digital social media platforms as it allows fans to be engaged and engrossed in the activities of their club on a more frequent basis. Social media provided the management of sport clubs with new means to promote their club interests and the extent of their reach to communities of fans have been significantly amplified (Witkemper et al., 2012). The researchers argued that groups of fans who frequently make use of social media would experience greater levels of fan engagement than those who did not.

Results supported both stated hypotheses, namely, (1) that fans that form part of an organised supporters' branch would 
experience greater levels of engagement than those who do not and (2) that fans that frequent the club's social media platforms will experience greater levels of engagement than those who do not. Through multigroup CFA and latent variable modelling, support for both hypotheses was established. Measurement invariance was established to compare the equivalence of measurement between the groups and to support findings.

The positive results in terms of the stated hypotheses also provided support for market segmentation theory and literature, particularly from the perspective of sport consumerism. Wedel and Kamakura (2012) have argued that differentiating between groups of consumers relating to their attributes, behaviours and demographic profiling has become a non-negotiable part of brand extension and commercial growth. In this regard, the study proved important in the realm of the sport consumer setting.

\section{Practical implications}

In the case of supporters' branches and congruent with the work of Millward (2012), the results supported a case for the expansion of supporters' branch structures as a means of enhancing the engagement experience of fans. Evidently from the analysis, fans that were part of organised branches were more inclined to experience engagement than those who were not. These fans should display the corporate citizenship behaviours associated with positive ambassadorship to the club's interests (Zagnoli \& Radicchi, 2009). The current research found higher levels of engagement amongst fans from supporters' branches on all dimensions of fan engagement, with the highest level of engagement being observed on the management cooperation factor. This suggests that engaged fans from supporters' branches are particularly interested in being involved in the strategic decisions and operation of the club (Auh et al., 2007; Yoshida et al., 2014).

Clubs are encouraged to attract more fans to their organised supporters' branches. Clubs must thus ensure that the possibility of joining a supporters' branch is an attractive and appealing value option to the fan. In line with $\mathrm{CE}$ - and relationship marketing theory, a strong value proposition to fans with clear emotional appeal will inspire long-term loyalty and ultimately lead to enhanced investment of timeous and monetary resources in the activities of that club. This will strengthen the role of the fan as commercial partner and bolster the club's commercial and social interests in a positive reciprocal process (Brodie et al., 2011).

Professional sport clubs are encouraged to utilise supporters' branches as vehicles to provide value to their fans and engage this important stakeholder to promote the club's interests. This can be achieved by enhancing the offerings of supporters' branches in the local regions operating on behalf of the club. Examples may include giving fans in supporters' branches access to special offers on club products, providing these fans with the opportunity to meet and interact with important role players from the club and providing a platform to these fans to give input on the strategic direction the club needs to take, for example, by giving supporters' branch members special access to give input on the club's opinion and feedback platforms.

As far as social media platforms were concerned, professional sport clubs are encouraged to direct a more concerted effort in their offerings as to engage a larger fraternity of fans. The comments of McCarthy et al. (2014) are strongly supported by the authors and corroborated by the research results: Management teams of sport clubs have no choice but to design comprehensive social media strategies should they wish to capture the attention of their fans and engage them to be true commercial partners to the interests of the club. These strategies must be robust and wide-ranging, but also flexible enough to cater for the array of individual needs constituted in the fan population (De Mel \& Boccardo, 2014; Witkemper et al., 2012). The dimension of fan engagement that was proven as most relevant to the social media use group was prosocial behaviour - suggesting a keen interest for interacting with others (Yoshida et al., 2014).

Key questions in designing a social media strategy may include: How do we create an attractive and appealing digital interface for fans through our social media platforms? How do we ensure our social media offerings strengthen the perception that our fans are our commercial partners? How do we enhance the voice of our fans in important strategic decisions of the club through our social media platforms? How do we positively contribute to our fans' need to interact with each other on social media? Interventions on this level are many and varied, but may include creating formal virtual discussion rooms where fans can converse on a particular topic, such as the latest team selection. It could also include launching mobile product offerings from the social media platforms, such as applications that make it possible for fans to compete with each other in predicting which team will be selected for an upcoming game. It could potentially include a simple intervention such as having fans establish mobile forums to debate and decide on the team's jersey design for the new season. The club that wishes to enhance the engagement experience of fans and mobilise these individuals to be true commercial partners must compile and resource comprehensive social media strategies that offer real value.

\section{Limitations and future research}

The study was not without limitations. Its cross-sectional nature poses the risk of common-method bias (Salkind, 2009). It may be useful to introduce a longitudinal approach to evaluate the possible changes observed in different groups of fans relating to their engagement experience over time. The study also attempted to address a research gap that has existed insofar as the engagement strategies of fans are concerned on a practical level. The two clusters of fans that were studied in this research were informed by the frequency and relative well-known nature of both supporters' branches and social media as tools that 
professional sport clubs use to communicate with fans. This does not imply that supporters' branches and social media are the only engagement strategies available to clubs to engage with fans. Future research should expand on further pragmatic applications of ideas that could drive the fan engagement experience. Finally, this research was conducted amongst fans of one of South Africa's best supported football clubs. This was based on the status the sport enjoys as South Africa's most followed sport (Saayman \& Rossouw, 2008). Future studies should be conducted amongst fans of some of the country's other major forms of sport to evaluate whether similar findings are found and to investigate further strategies aimed at enhancing fan engagement.

\section{Conclusion}

Results revealed differences in fan engagement observed between groups of fans. This provides a basis that supports the promotion of the fan engagement experience through practical interventions. In this study, both supporters' branches and use of social media were put forward as vehicles that clubs could potentially use to enhance the engagement of fans. Both revealed potential value and were subsequently discussed from a pragmatic perspective. Future research should focus on further practical strategies that could enhance the fan engagement experience and should assess these strategies on the basis of clearly defined performance indicators.

\section{Acknowledgements Competing interests}

The authors declare that they have no financial or personal relationships which may have inappropriately influenced them in writing this article.

\section{Authors' contributions}

F.W.S. was the research project leader and corresponding author. L.T.d.B. was a co-author and methodical expert to the work.

\section{References}

Allison, N. (2013). Going beyond on-pitch success: Fan engagement as a catalyst for growth. Birkbeck Sport Business Centre Research Paper Series, 6(2), London, UK: Birkbeck, University of London.

Auh, S., Bell, S.J., McLeod, C.S., \& Shih, E. (2007). Co-production and customer loyalty in financial services. Journal of Retailing, 83(3), 359-370. http://dx.doi. org/10.1016/j.jretai.2007.03.001

Bale, J. (1993). The spatial development of the modern stadium. International Review for the Sociology of Sport, 28(2-3), 121-133. http://dx.doi.org/10.1177/10126 9029302800204

Baller, S. (2015). Global perspectives on football in Africa. London: Routledge.

Bee, C.C., \& Kahle, L.R. (2006). Relationship marketing in sports: A functional approach. Sport Marketing Quarterly, 15(2), 101-111.

Berry, L.L. (1983). Relationship marketing. Chicago, IL: American Marketing Association.

Bing, Z., Li, Y., Miao, T., ZiWen, W., XueFeng, C., Lu, L., et al. (2015). Sports industry and tourism integrative development effectiveness prediction. Journal of Chemical and Pharmaceutical Research, 7(3), 1867-1872.

Bouzdine-Chameeva, T., Ferrand, A., Valette-Florence, P., \& Chanavat, N. (2015). Measurement and segmentation of sport fans using brand association networks: Application to Union of European Football Associations (UEFA) Champions League (UCL). Sport Management Review, 18(3), 407-420. http://dx.doi.org/10.1016/j. smr.2014.11.002
Brodie, R.J., Hollebeek, L.D., Juric, B., \& Ilic, A. (2011). Customer engagement: Conceptual domain, fundamental propositions, and implications for research. Journal of Service Research, 14(3), 252-271. http://dx.doi.org/10.1177/ Journal of Service
1094670511411703

Cohen, J. (1988). Statistical power analysis for the behavioral sciences. (2nd edn.). Hillsdale, NJ: Lawrence Earlbaum Associates.

Cottingham, M., Phillips, D., Hall, S.A., Gearity, B.T., \& Carroll, M.S. (2014). Application of the motivation scale for disability sport consumption: An examination of intended future consumption behavior of collegiate wheelchair basketball spectators. Journal of Sport Behavior, 37(2), 117-124.

Crawford, G. (2004). Consuming sport: Sport, fans and culture. London: Routledge.

Crawford, G. (2009). Consuming sport, consuming beer: Sport fans, scene and everyday life. In L.A. Wenner, \& S.J. Jackson (Eds.), Sport, beer, and gender: Promotional culture \& contemporary social life, New York, NY: Peter Lang Publishing.

Cross, J.C., Belich, T.J., \& Rudelius, W. (2015). How marketing managers use market segmentation: An exploratory study. In Proceedings of the 1990 Academy of Marketing Science (AMS) Annual Conference (pp. 531-536). New York, NY: Springer International Publishing.

De Burca, S., Brannick, T., \& Meenaghan, T. (2015). Spectators as consumers-the motivating forces. In Proceedings of the 1993 World Marketing Congress (pp. 644-648). New York, NY: Springer International Publishing.

De Mel, S., \& Boccardo, A. (2014). Social interactions as brand benefits: A sport marketing approach. World, 4(2), 30-46.

De Ruyter, K., \& Wetzels, M. (2000). Customer equity considerations in service recovery: A cross-industry perspective. International Journal of Service Industry Management, 11(1), 91-108. http://dx.doi.org/10.1108/09564230010310303

Doherty, Y. (2013). Investing in sport management: The value of good theory. Sport Management Review, 16(1), 5-11. http://dx.doi.org/10.1016/j. smr.2011.12.006

Fillis, I., \& Mackay, C. (2014). Moving beyond fan typologies: The impact of social integration on team loyalty in football. Journal of Marketing Management, 30(3-4), 334-363. http://dx.doi.org/10.1080/0267257X.2013.813575

Funk, D.C., Beaton, A., \& Alexandris, K. (2012). Sport consumer motivation: Autonomy and control orientations that regulate fan behaviours. Sport Management Review, 15(3), 355-367. http://dx.doi.org/10.1016/j.smr.2011.11.001

Giampiccoli, A., Lee, S.S., \& Nauright, J. (2015). Destination South Africa: Comparing global sports mega-events and recurring localised sports events in South Africa for tourism and economic development. Current Issues in Tourism, 18(3), 229-248. http://dx.doi.org/10.1080/13683500.2013.787050

Guimaraes, G., Stride, C., \& O'Reilly, D. (2016). Brand community, loyalty and promise in myfootballclub.co.uk. Sport, Business and Management: An promise in myfootballclub.co.uk. Sport, Business and Management: An
International Journal, 6(2), 137-157. http://dx.doi.org/10.1108/SBM-09-20120039

Hall, K. (2009, November 30-December 2). A model of predictors of attendance at major sporting events. Paper presented at the Australian and New Zeeland Marketing Academy, Monash University, Melbourne.

Heere, B., \& James, J.D. (2007). Sports teams and their communities: Examining the influence of external group identities on team identity. Journal of Sport Management, 21(3), 319-323.

Hollebeek, L.D., Conduit, J., \& Brodie, R.J. (2016). Strategic drivers, anticipated and unanticipated outcomes of customer engagement. Journal of Marketing Management, 32(5-6), 393-398.

Hollensen, S. (2015). Marketing management: A relationship approach. London, UK Pearson Education.

Hu, C., \& Cole, S. (2016). Comparing expenditure patterns and travel characteristics among NFL fans with different levels of team identification. Tourism Review International, 20(1), 3-10. http://dx.doi.org/10.1080/0267257X.2016. 1144360

Humphries, C.E., \& Smith, A.C. (2006). Sport fandom as an occupation: Understanding the sport consumer through the lens of occupational science. International Journal of Sport Management and Marketing, 1(4), 331-348. http://dx.doi. org/10.1504/IJSMM.2006.010565

Hunt, S.D., \& Arnett, D.B. (2004). Market segmentation strategy, competitive advantage, and public policy: Grounding segmentation strategy in resource advantage, and public policy: Grounding segmentation strateg
advantage theory. Australasian Marketing Journal, 12(1), 7-25.

Jenkins, M., \& McDonald, M. (1997). Market segmentation: Organisational archetypes and research agendas. European Journal of Marketing, 31(1), 17-30. http://dx. doi.org/10.1108/03090569710157016

Katz, M., \& Heere, B. (2015). Empowerment within brand communities: Overcoming the Achilles' Heel of scale-free networks. Sport Management Review, 18(3), 370-383. http://dx.doi.org/10.1016/j.smr.2014.10.001

Koenderman, T. (2013). Tough times for sponsored sport. Finweek, 2, 50-51.

Koortzen, P., \& Oosthuizen, R.M. (2012). Psychological experiences in South African society before the 2010 FIFA World Cup from the systems psychodynamic and positive psychology perspectives. SA Journal of Industrial Psychology, 38(2), 1-13. http://dx.doi.org/10.4102/sajip.v38i2.976

KPMG. (2014). Business of sports [Adobe Digital Editions Version]. Retrieved December 12, 2015 from https://www.kpmg.com/IN/en/IssuesAndlnsights/ ArticlesPublications/Documents/Business-of-Sports.pdf

Leonardi, P.M., Huysman, M., \& Steinfield, C. (2013). Enterprise social media: Definition, history, and prospects for the study of social technologies in
organizations. Journal of Computer-Mediated Communication, 19(1), 1-19. http://dx.doi.org/10.1111/jcc4.12029 
Madden, P. (2012). Fan welfare maximization as a club objective in a professional sports league. European Economic Review, 56(3), 560-578. http://dx.doi. org/10.1016/j.euroecorev.2011.12.006

Madrigal, L., Hamill, S., \& Gill, D.L. (2013). Mind over matter: The development of the Mental Toughness Scale (MTS). The Sport Psychologist, 27, 62-77.

Martin, C.A. (2013). Investigating National Football League (NFL) fan loyalty. Journal of Marketing Development and Competitiveness, 7(1), 42-53.

McCarthy, J., Rowley, J., Jane Ashworth, C., \& Pioch, E. (2014). Managing brand presence through social media: The case of UK football clubs. Internet Research, 24(2), 181-204. http://dx.doi.org/10.1108/IntR-08-2012-0154

Millward, P. (2012). Reclaiming the Kop? Analysing Liverpool supporters' 21st century mobilizations. Sociology, 46(4), 633-648. http://dx.doi.org/10.1177/0038038511 425557

Monfarde, F.T., Tojari, F., \& Nikbakhsh, R. (2014). Constraints and motivators of sport consumption behavior. Bulletin of Environment, Pharmacology and Life Sciences, 3(3), 308-312.

Morgan, R.M., \& Hunt, S.D. (1994). The commitment-trust theory of relationship marketing. The Journal of Marketing, 58(3), 20-38. http://dx.doi.org/10.2307/ 1252308

Muthén, L.K., \& Muthén, B.O. (2015). Mplus user's guide. (7th edn.). Los Angeles, CA Muthén \& Muthén.

O'Shea, M., \& Alonso, A.D. (2012). Opportunity or obstacle? A preliminary study of professional sport organisations in the age of social media. International Journal of Sport Management and Marketing, 10(3-4), 196-212.

Pichot, L., Tribou, G., \& O’Reilly, N. (2008). Sport sponsorship, internal communications, and human resource management: An exploratory assessment of potential future research. International Journal of Sport Communication, 1(4), 413-423.

Pillay, U., \& Bass, O. (2009). Mega-events as a response to poverty reduction: The 2010 FIFA World Cup and urban development implications. In B. Pillay, R. Tomlinson, \& O. Bass (Eds.), Development and dreams: The urban legacy of the 2010 Football World Cup. Cape Town: HSRC Press.

PricewaterhouseCoopers. (2015). Entertainment and media outlook: 2014-2018 [Adobe Digital Editions Version]. Retrieved December 12, 2015, from https://www. pwc.co.za/en/assets/pdf/entertainment-and-media-outlook-2014- 2018.pdf

Saayman, M., \& Rossouw, R. (2008). The economic value of the 2010 Soccer World Cup. Retrieved Mar. 12, 2014, from http://www.actacommercii.co.za/index.php/ acta/article/viewFile/55/55

Salkind, N.J. (2009). Pre-and true experimental research methods. Exploring Research pp.225-242, New York, NY: Pearson.

Shank, M.D., \& Lyberger, M.R. (2014). Sports marketing: A strategic perspective. London: Routledge.
Stander, F.W., \& De Beer, L.T. (2016). Engagement as a source of positive consumer behaviour: A study amongst South African football fans. South African Journal for Research in Sport, Physical Education and Recreation, 38(2), 1-10.

Stander, F.W., \& Van Zyl, L.E. (2016). See you at the match: Motivation for sport consumption and intrinsic psychological reward of premier league footbal spectators in South Africa. South African Journal of Industrial Psychology, 42(1), $1-12$.

Trail, G.T., \& James, J.D. (2001). The motivation scale for sport consumption: A comparison of psychometric properties with other sport motivation scales. Journal of Sport Behavior, 24(1), 108-127.

Van de Schoot, R., Lugtig, P., \& Hox, J. (2012). A checklist for testing measurement invariance. European Journal of Developmental Psychology, 9(4), 486-492. http:// dx.doi.org/10.1080/17405629.2012.686740

Van Doorn, J., Lemon, K.N., Mittal, V., Nass, S., Pick, D., Pirner, P., et al. (2010) Customer engagement behavior: Theoretical foundations and research directions. Journal of Service Research, 13, 253-266. http://dx.doi.org/10.1177/ 1094670510375599

Vohra, A., \& Bhardwaj, N. (2016). A conceptual presentation of customer engagement in the context of social media - An emerging market perspective. Internationa Journal in Management \& Social Sciences, 4(1), 351-366.

Wang, R.T., Zhang, J.J., \& Tsuji, Y. (2011). Examining fan motives and loyalty for the Chinese Professional Baseball League of Taiwan. Sport Management Review, 14, 347-360. http://dx.doi.org/10.1016/j.smr.2010.12.001

Wann, D.L., Melnick, M.J., Russell, G.W., \& Pease, D.G. (2001). Sport fans: The psychology and social impact of spectators. London: Routledge.

Wedel, M., \& Kamakura, W.A. (2012). Market segmentation: Conceptual and methodological foundations, Vol. 8., New York, NY: Springer Science \& Business Media.

Witkemper, C., Lim, C.H., \& Waldburger, A. (2012). Social media and sports marketing Examining the motivations and constraints of Twitter users. Sport Marketing Quarterly, 21(3), 170-183.

Yoshida, M., Gordon, B., Heere, B., \& James, J.D. (2015). Fan community identification: An empirical examination of its outcomes in Japanese professional sport. Sport Marketing Quarterly, 24(2), 105-110. http://dx.doi.org/10.1123/ jsm.2013-0199

Yoshida, M., Gordon, B., Nakazawa, M., \& Biscaia, R. (2014). Conceptualization and measurement of fan engagement: Empirical evidence from a professional sport context. Journal of Sport Management, 28(4), 399-417.

Zagnoli, P., \& Radicchi, E. (2009). Do major sports events enhance tourism destinations? Physical Culture and Sport: Studies and Research, 47(1), 44-63. http://dx.doi.org/10.2478/v10141-009-0031-z 